CARNETS OE Carnets de géographes

GÉOGRAPHES.

2| 2011

Espaces virtuels

\title{
Le zoo comme dispositif spatial
}

Pour une géographie culturelle de l'animalité

Jean Estebanez

\section{(2) OpenEdition}

Journals

Édition électronique

URL : http://journals.openedition.org/cdg/2881

DOI : $10.4000 /$ cdg. 2881

ISSN : 2107-7266

Éditeur

UMR 245 - CESSMA

Référence électronique

Jean Estebanez, «Le zoo comme dispositif spatial », Carnets de géographes [En ligne], 2 | 2011, mis en ligne le 02 mars 2011, consulté le 07 mai 2019. URL : http://journals.openedition.org/cdg/2881 ; DOI : $10.4000 /$ cdg.2881

Ce document a été généré automatiquement le 7 mai 2019.

\section{(c)}

La revue Carnets de géographes est mise à disposition selon les termes de la Licence Creative Commons Attribution - Pas d'Utilisation Commerciale - Pas de Modification 4.0 International. 


\title{
Le zoo comme dispositif spatial
}

\author{
Pour une géographie culturelle de l'animalité
}

\author{
Jean Estebanez
}

Plus de 600 millions de personnes, d'origine sociale très variée, visitent tous les ans des zoos, dans une pratique qui apparaît quasiment universelle (seul 43 pays dans le monde ne posséderaient aucun établissement). Peu d'enjeux forts semblent les caractériser, en dehors peut-être de questions liées à l'éthique de l'enfermement des animaux. D'après leur présentation officielle, les zoos sont des lieux orientés vers un public familial, mêlant fonction éducative et divertissement.

2 Pourtant les zoos organisent le vivant et le monde, à travers la constitution de collections en fonction de critères taxonomiques, écologiques, à partir de découpages par continent ou de valeur d'exposition. L'exotisme et la sauvagerie sont deux éléments constitutifs des zoos, qu'il faut analyser à l'aune de leurs liens avec la colonisation. L'exotisme est une forme d'altérité géographique qui ne s'inscrit pas dans une localisation mais dans l'écart à une norme implicite, construite par une société dominante. La sauvagerie recoupe une variété de significations -du féroce à l'authentique- qui reflète une vision changeante des animaux et de la nature. Aucun animal n'étant par essence exotique ou sauvage, cette thèse analyse le zoo comme un dispositif spatial, capable de produire du sens et de le projeter sur ce qu'il présente. Le concept de dispositif, proposé par Foucault, a le grand intérêt de ne pas réduire un lieu à son architecture mais de le réinsérer dans un système hétérogène de règlements, de discours, d'outils et de technologies et ainsi de penser l'articulation entre matériel et symbolique.

Les zoos peuvent être analysés comme des théâtres du vivant dont la fonction principale est de montrer à travers scène, fosse, rideau, acteurs-animaux, public et mise en scène. Un des éléments centraux de cette pièce est la relation entre les humains et les animaux. Dans des institutions qui tracent une dichotomie claire entre eux, comment peut-on penser le cas des zoos humains et leur déclinaison contemporaine (des signes d'activité humaine dans les enclos)? Des grilles aux vitres, en passant par les fosses, l'histoire architecturale des zoos reflète une pensée changeante des relations entre humains et animaux, qui s'exprime à travers l'établissement d'une juste distance. L'institution, comme le public, testent continuellement cette frontière entre les êtres. Le zoo n'est-il 
pas au fond un lieu où expérimenter cette question métaphysique: qu'est-ce qu'être humain?

4 Cette thèse s'appuie sur une analyse de la littérature et la visite d'environ 50 zoos dans 22 pays (Australie, Chili, Etats-Unis, Ethiopie, France, Japon...). Plusieurs semaines d'entretiens et d'observations en situation auprès des différents acteurs des zoos et près de 10000 photographies constituent le fond de mon corpus.

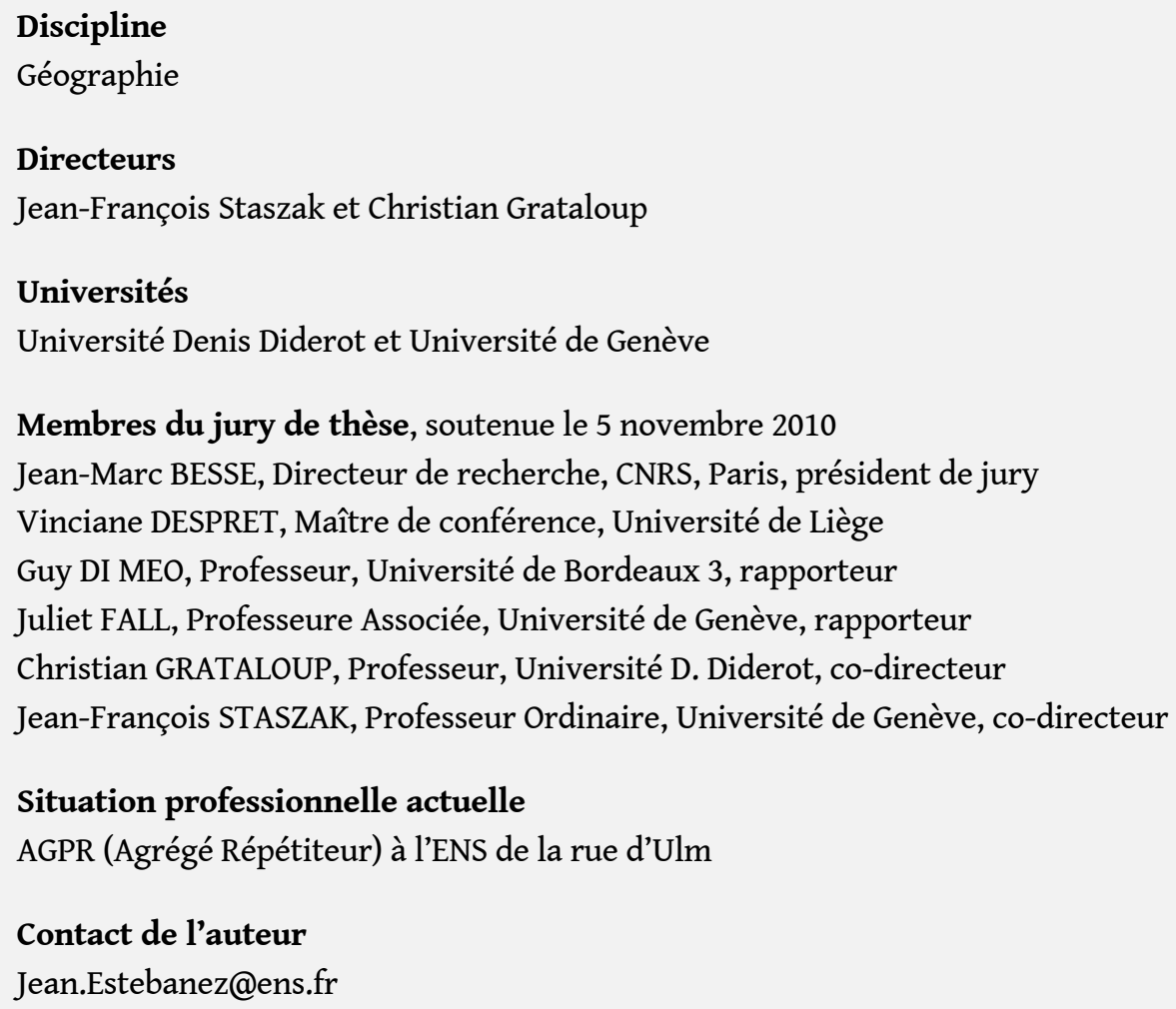

\section{BIBLIOGRAPHIE}

Estebanez J., 2010, "Le zoo comme dispositif spatial : mise en scène du monde et de la juste distance entre l'humain et l'animal", L'Espace Géographique, 2, pp. 172-179

\section{INDEX}

Thèmes : Carnets de soutenances 